\title{
Design and development of ultra-light front and rear axle of experimental vehicle
}

https://doi.org/10.1515/eng-2020-0032

Received Sep 02, 2019; accepted Oct 30, 2019

\begin{abstract}
Shell Eco-marathon is an international competition to develop a vehicle with the lowest fuel consumption. The Faculty of Mechanical Engineering of the Technical University in Košice has been involved in this competition for 25 years, during which it developed 8 vehicles. For vehicles are important not only low fuel consumption but also high safety. In addition to the low aerodynamic drag of the vehicle, the low weight of the vehicle is important to achieve low fuel consumption. This is achieved by using ultra-light and solid materials in all parts of the vehicle. The latest generation vehicle uses a self-supporting body, which has increased requirements for front and rear stiffness, as discussed in this article.
\end{abstract}

Keywords: axle, material, ultra-light vehicle, weight, simulation

\section{Introduction}

One of the most important elements of a Shell eco marathon race is to build the vehicle with the lowest possible weight, so special materials are used for this purpose [1]. The body is self-supporting and made by using special carbon materials. A special manufacturing process was used to ensure a small body thickness while maintain-

\footnotetext{
*Corresponding Author: Ludmila Pavlikova: Technical University of Kosice, Faculty of Economics, Department of Banking and Investment Letná 9, 04200 Kosice, Slovak Republic;

Email: maros.palko@tuke.sk

*Corresponding Author: Jan Kral: Technical University of Kosice, Faculty of Mechanical Engineering, Department of Production Systems, Letná 9, 04200 Kosice, Slovak Republic;

Email: jan.kral.2@tuke.sk

Miroslav Palko: Technical University of Kosice, Faculty of Mechanical Engineering, Department of Production Systems, Letná 9, 04200 Kosice, Slovak Republic; Email: miroslav.palko@tuke.sk

Maroš Palko: Technical University of Kosice, Faculty of Mechanical Engineering, Department of Production Systems, Letná 9, 04200 Kosice, Slovak Republic; Email: maros.palko@tuke.sk
}

○ Open Access. (C) 2020 J. Kral et al., published by De Gruyter. (Cc) BY License ing the highest rigidity [2]. All components used in this experimental vehicle were selected using several criteria, the most important being quality and the lowest possible weight. The placement of the individual components was proceeded in accordance with the idea of keeping the center of gravity of the vehicle as low as possible to ensure sufficient vehicle stability [3]. Since the race takes place on a multi-turn circuit, in addition to the low weight and sufficient rigidity of the vehicle, it is very important to have the correct geometry of the turning wheels [4]. When cornering, each of the steered wheels travels in a different path, due to the inner and outer wheels passing the bend below a different turning radius. To achieve the best result in this competition, all possible passive resistances and losses should be eliminated as much as possible. One of these losses can be caused by the poor geometry of the steered wheels, which can cause the steered wheels to brake the entire vehicle when cornering $[5,6]$. Despite the fact that the ultra-light vehicle does not have dampers, it was necessary to think about the stiffness of the axle so that it could to some extent support the wheel and return to the original position [7-9]. An important factor for the success of these races is not only to build a low consumption engine, but also to reduce wheel resistance, especially when cornering $[10,11]$. Another inseparable part in the development of the experimental vehicle is the aerodynamic drag of the body, which has a great influence on its speed, stability but especially on fuel consumption [12,13]. The exterior aerodynamic shape of the bodywork must be designed to provide the best possible airflow and at the same time provide sufficient space for the driver to have sufficient visibility outside and to accommodate all the necessary components $[14,15]$.

\section{Problem description}

\subsection{Front axle}

The geometry is the most important thing on front axle. Correct geometry adjustment ensures smooth rolling when 


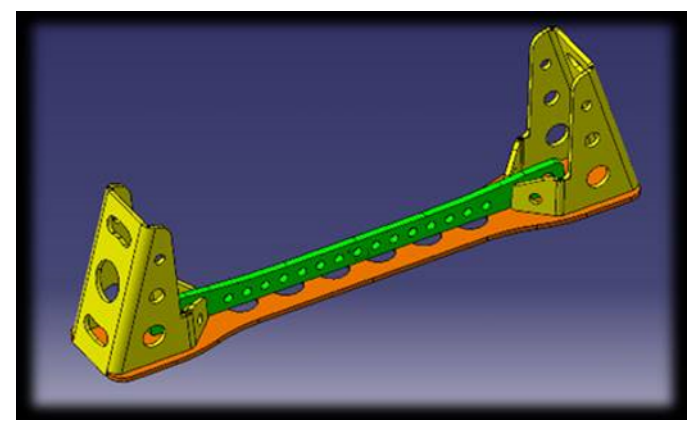

Figure 1: Front axle 2018.

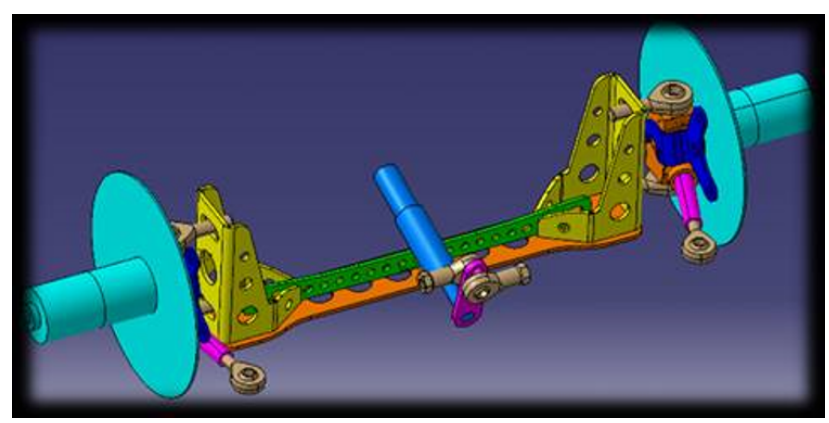

Figure 2: Front axle 2018.

Table 1: Characteristics of aluminium 5754.

\begin{tabular}{lll}
\hline Property & Value & Units \\
\hline Elastic Modulus & $7 \mathrm{e}+10$ & $\mathrm{~N} / \mathrm{m}^{2}$ \\
Poisson's Ratio & 0.3897 & $\mathrm{~N} / \mathrm{A}$ \\
Shear Modulus & $2.7 \mathrm{e}+10$ & $\mathrm{~N} / \mathrm{m}^{2}$ \\
Mass Density & 2660 & $\mathrm{~kg} / \mathrm{m}^{3}$ \\
Tensile Strength & 290000000 & $\mathrm{~N} / \mathrm{m}^{2}$ \\
Compressive Strength & & $\mathrm{N} / \mathrm{m}^{2}$ \\
Yield Strength & 250000000 & $\mathrm{~N} / \mathrm{m}^{2}$ \\
Thermal Expansion Coefficient & $2.4 \mathrm{e}-05$ & $/ \mathrm{K}$ \\
\hline
\end{tabular}

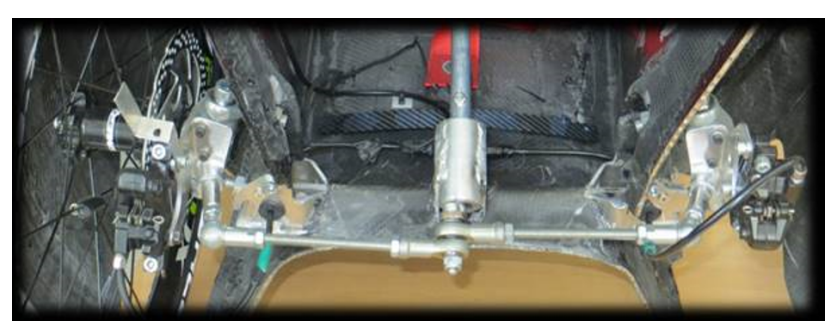

Figure 3: Laminated front axle.

the steering wheel turns. To fulfil this condition, we used the system Causant to ensure this condition.

When developing the new front axle, in addition to the correct adjustment, the main aim was put to the lowest possible weight at the highest possible rigidity. The basic point was to choose a suitable material.

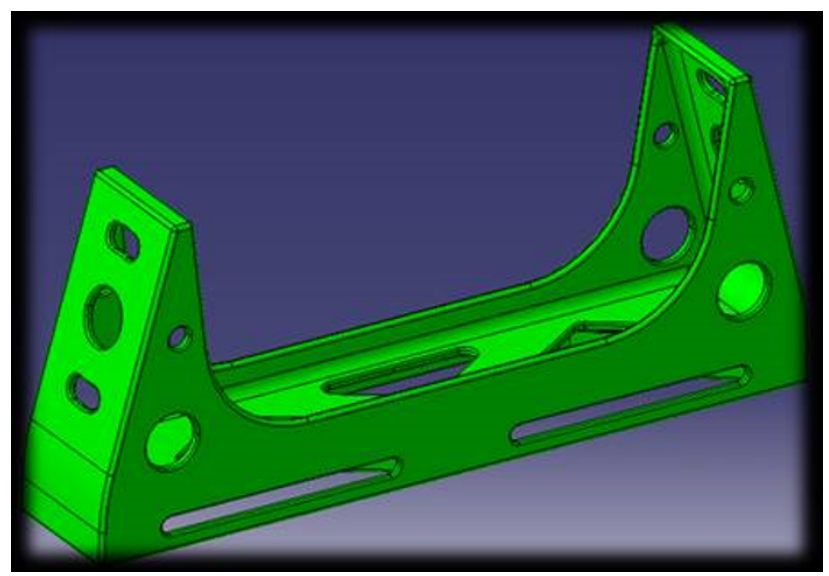

Figure 4: Front axle 2019.

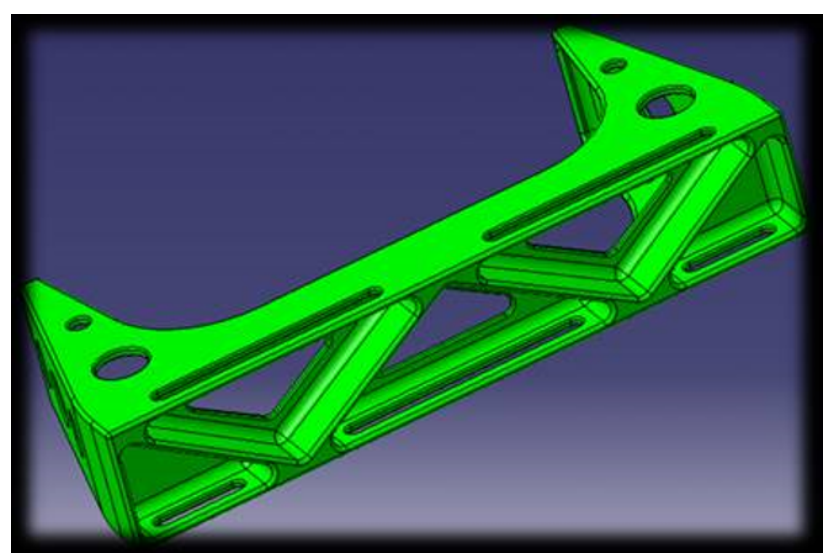

Figure 5: Front axle 2019.

Table 2: Characteristic of duralumin alloy 7075.

\begin{tabular}{lll}
\hline Property & Value & Units \\
\hline Elastic Modulus & $7.19999992 \mathrm{e}+10$ & $\mathrm{~N} / \mathrm{m}^{2}$ \\
Poisson's Ratio & 0.33 & $\mathrm{~N} / \mathrm{A}$ \\
Shear Modulus & $2.689999969 \mathrm{e}+10$ & $\mathrm{~N} / \mathrm{m}^{2}$ \\
Mass Density & 2810.000061 & $\mathrm{~kg} / \mathrm{m}^{3}$ \\
Tensile Strength & 219999997.9 & $\mathrm{~N} / \mathrm{m}^{2}$ \\
Compressive Strength & & $\mathrm{N} / \mathrm{m}^{2}$ \\
Yield Strength & 94999999.42 & $\mathrm{~N} / \mathrm{m}^{2}$ \\
Thermal Expansion Coefficient & $2.4 \mathrm{e}-05$ & $/ \mathrm{K}$ \\
Thermal Conductivity & 173 & $\mathrm{~W} /(\mathrm{m} \cdot \mathrm{K})$ \\
\hline
\end{tabular}

For 2018, the front axle consisted of four separately laser-cutted and bent parts that were welded together to form the front axle (Figure 1). We choose aluminium 5754 (Figure 2) for its high strength, which approximates conventional steel at significantly lower weight. Another advantage of this material is its good weldability, which we used in this case. The simulations have shown that this construction solution will be a good fit for use in the Shell eco Marathon race. The front hubs were attached to the 


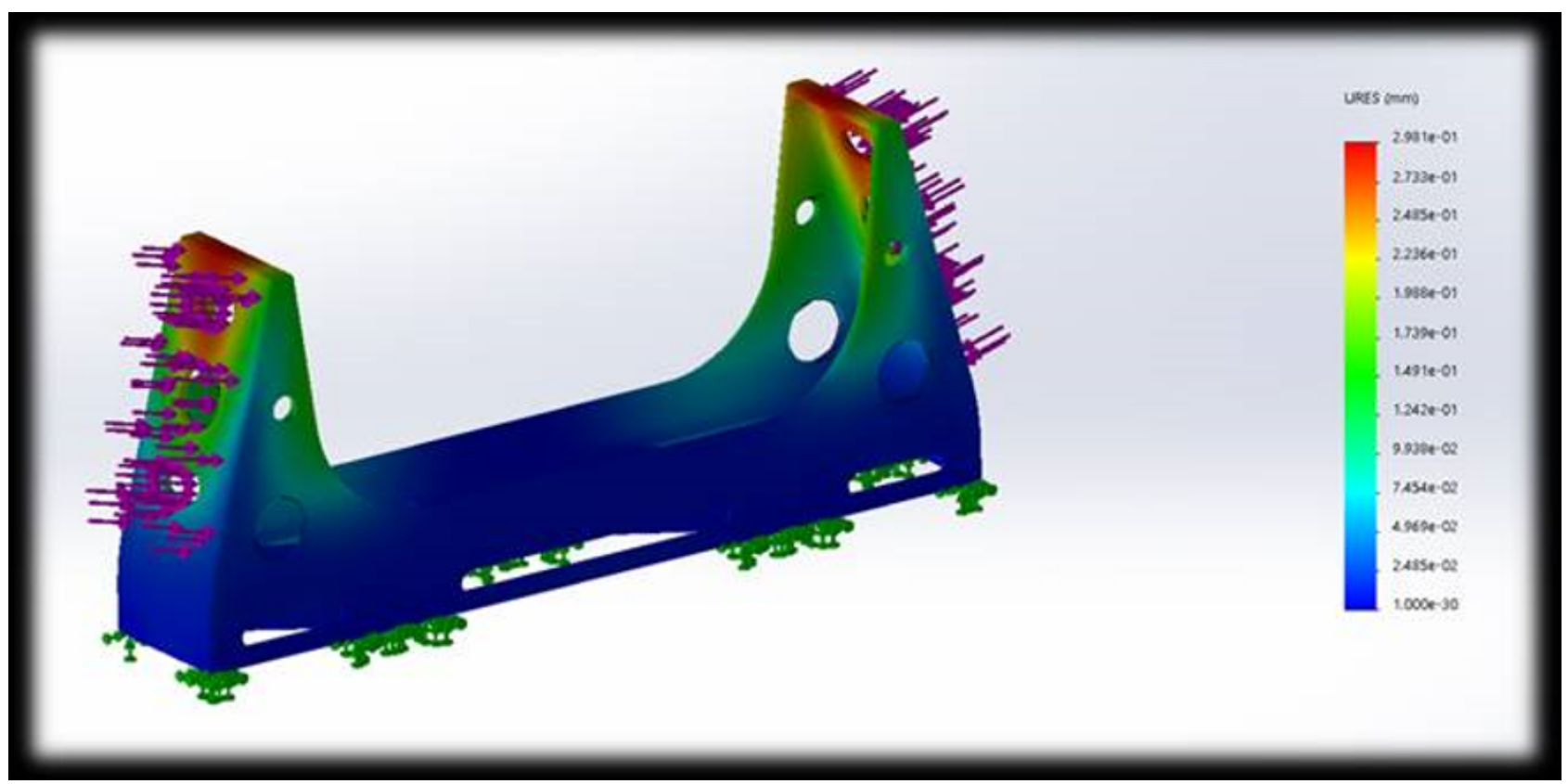

Figure 6: Deformation simulation of front axle 2019.

bevelled axle, for optimum deflection of the front wheels. The entire axle was then laminated to the self-supporting body and thus formed one unit (Figure 3). There were several collisions at the competition in that year, which, despite our assumptions about sufficient rigidity, led to deformation of the front axle.

Due to the unpredictable circumstances that may arise during competition, we approached the development of a new front axle for 2019, where we wanted to ensure even more rigidity, even at the cost of increased weight. We decided to abandon the original idea of welding the front axle from several parts, but to milled it straight from the duralumin alloy 7075 (Figure 4) in one piece (Figure 3). This material is mainly used in the aerospace industry for its high strength, where it overcomes conventional steels at a still relatively low weight. One of the disadvantages of this material is that it cannot be welded and therefore we chose the one-piece milling concept. The front axle for 2019, retained the dimensions and retaining hubs from 2018, where we have already tested the correct alignment of the front wheel geometry. The new front axle, with a weight of 750 grams more than axle from previous year, has a somewhat higher rigidity. When comparing deformation simulations (Figure 5, 6), it appears that the new front axle has the maximum possible displacement at the point of attachment of the front hubs by more than half less. The system of Causant management was also maintained for the year 2019.

\subsection{Rear axle}

The rear axle is not only used to support the rear wheel. Since only the rear wheel is driven, engine and gears are also mounted on this axle. Due to the small size of the vehicle, we also placed an electronic and fuel system on the rear axle (Figure 8).

For 2019, the rear axle was redesigned completely. The aim was to increase stiffness even more and reduce center of gravity while maintaining low weight.

However, we were still limited by the back of the body, which we could no longer modify.

As for the year 2019 we also modified the engine Honda GX 35, there was also a significant change in clutch and engine starter. The aluminium 5754 was chosen for the rear axle, the same as for the front axle in 2018. The rigidity of the rear axle was ensured by the system of bends that created the closed structure and additional reinforcements (Figure 8). Both these measures led to the rear axle being fitted with all the necessary components such as the engine starter, the control unit and the fuel system. At the same time, a new engine holder was designed so that the engine was placed as low as possible, thus ensuring the center of gravity shift as low as possible, and at the same time the engine holder became another reinforcement of the entire rear axle (Figure 10).

During the preparation of the vehicle for the race there were changes to the originally designed upper reinforcements, which we decided to fix by screws instead of weld- 


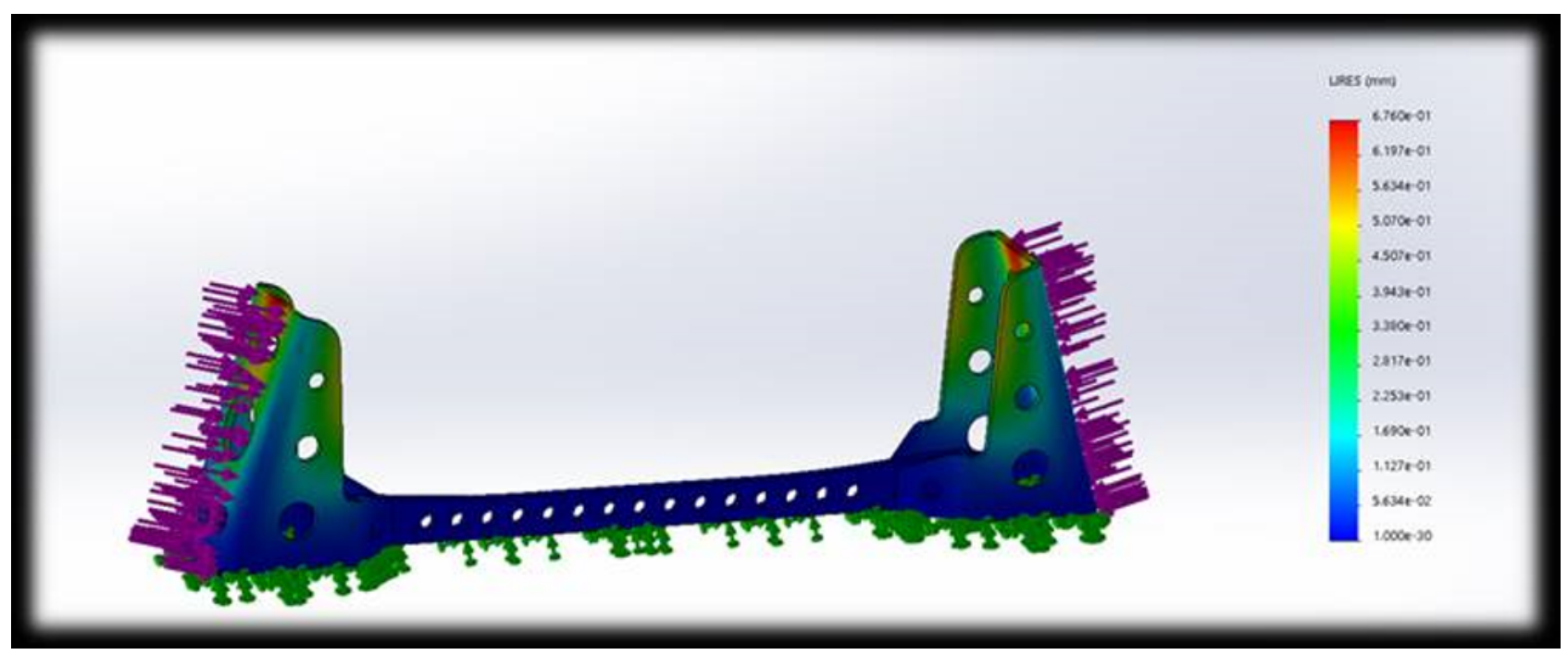

Figure 7: Deformation simulation of front axle 2018.

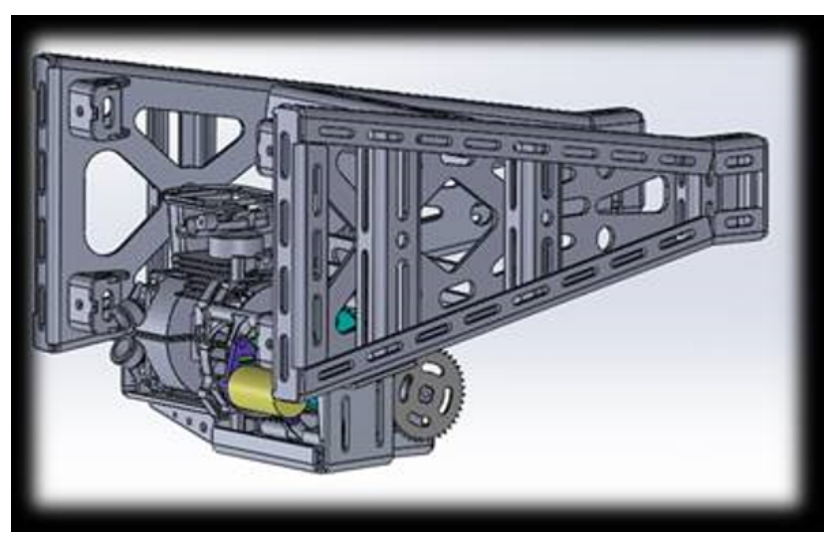

Figure 8: 3D model of rear axle with engine and gears.

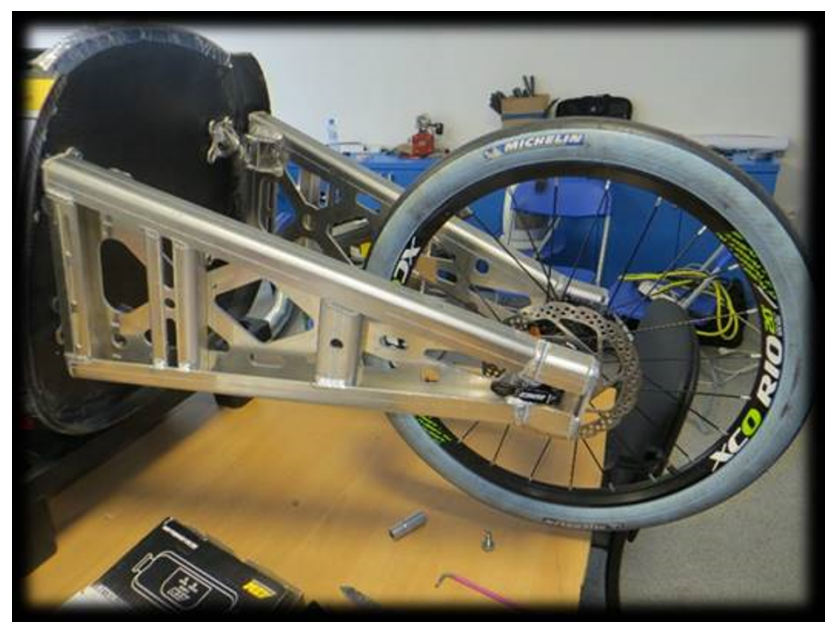

Figure 9: Rear axle without other accessories.

ing. Such a solution greatly facilitated access to the engine and all sensors if it is necessary during the race for repairs.

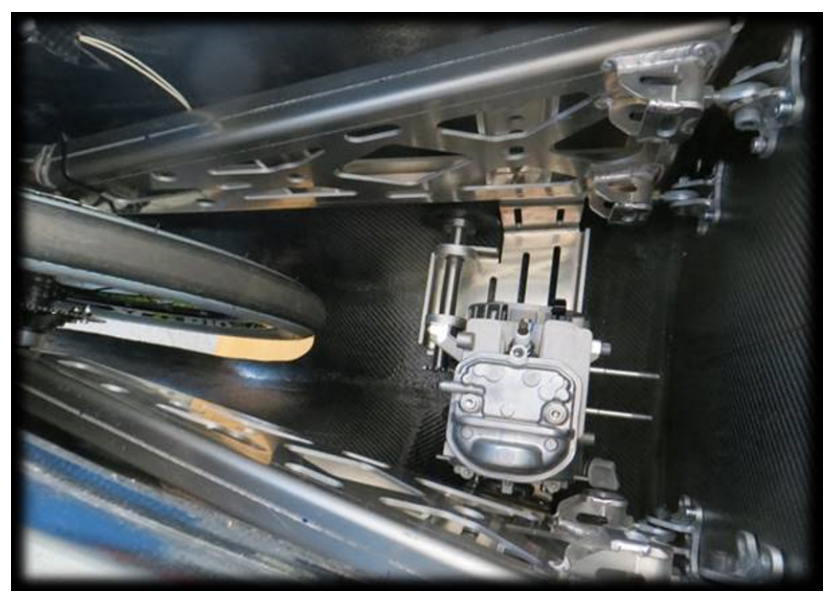

Figure 10: Engine holder.

At the same time, we used these reinforcements to locate the fuel transport system for the engine (Figure 11).

The change also involved the connection of the rear axle to the middle body section. The rear axle from 2018 was fixed to the center body plate using aluminium plates with threads laminated in the center body plate. The new rear axle for 2019 was designed with different mounting dimensions and therefore it was necessary to drill the central carbon plate, which we also reinforced with aluminium reinforcement, which prevented damage to the central plate (Figure 12, 13).

During the assembly we used all the free space, all the components fit perfectly and we managed to achieve the goal that we set before the construction.

As for the year 2019 we also modified the engine Honda GX 35, there was also a significant change in clutch 


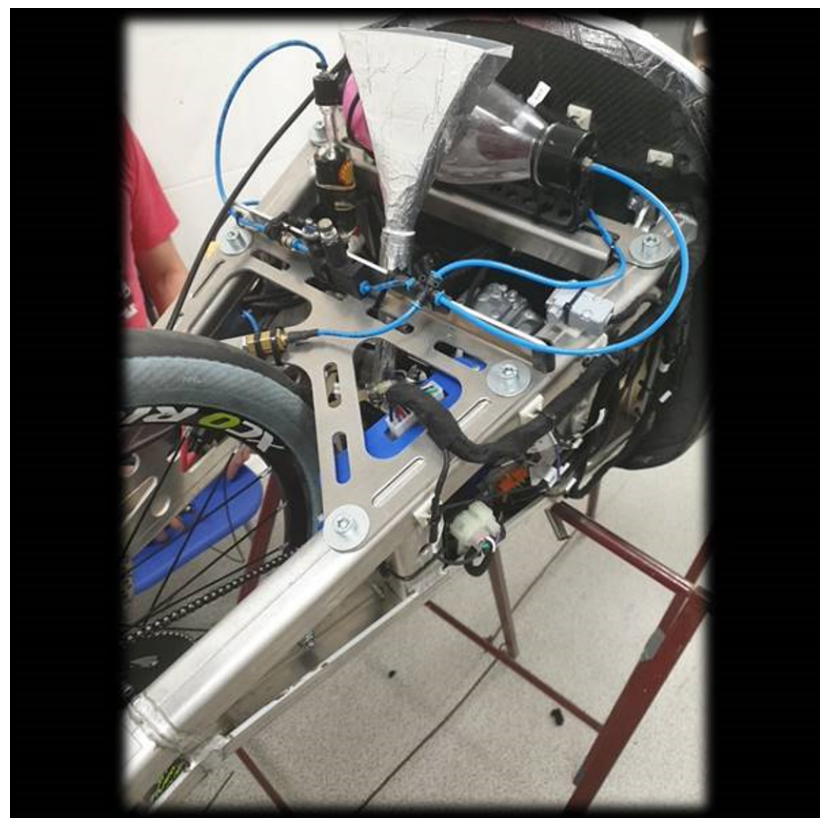

Figure 11: Whole assembly of rear axle.

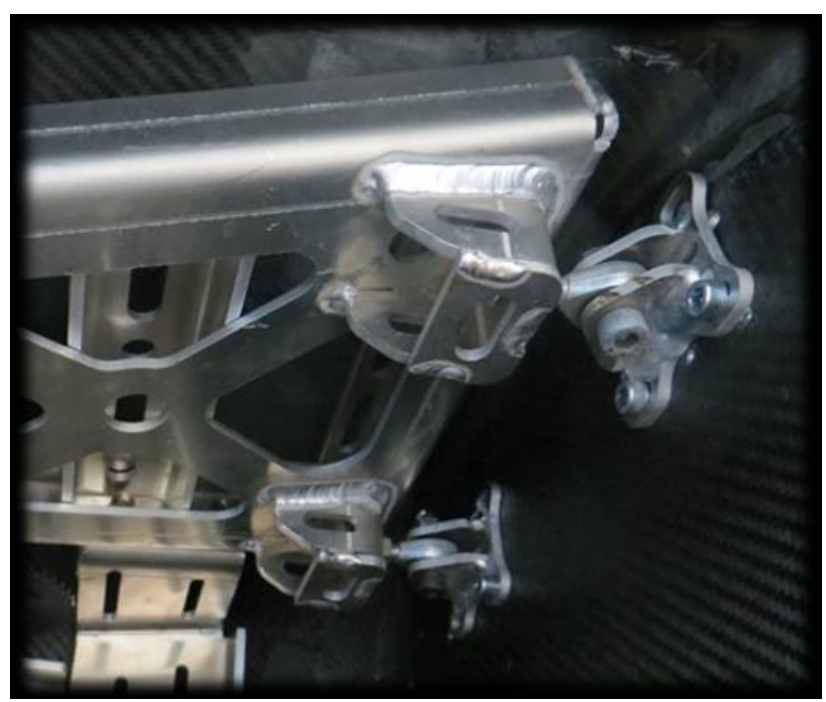

Figure 12: Connection of rear axle to central plate.

and engine starter. The aluminium 5754 was chosen for the rear axle, the same as for the front axle in 2018. The rigidity of the rear axle was ensured by the system of bends that created the closed structure and additional reinforcements (Figure 5). Both these measures led to the rear axle being fitted with all the necessary components such as the engine starter, the control unit and the fuel system. At the same time, a new engine holder was designed so that the engine was placed as low as possible, thus ensuring the center of gravity shift as low as possible, and at the same time the engine holder became another reinforcement of the entire rear axle (Figure 6).

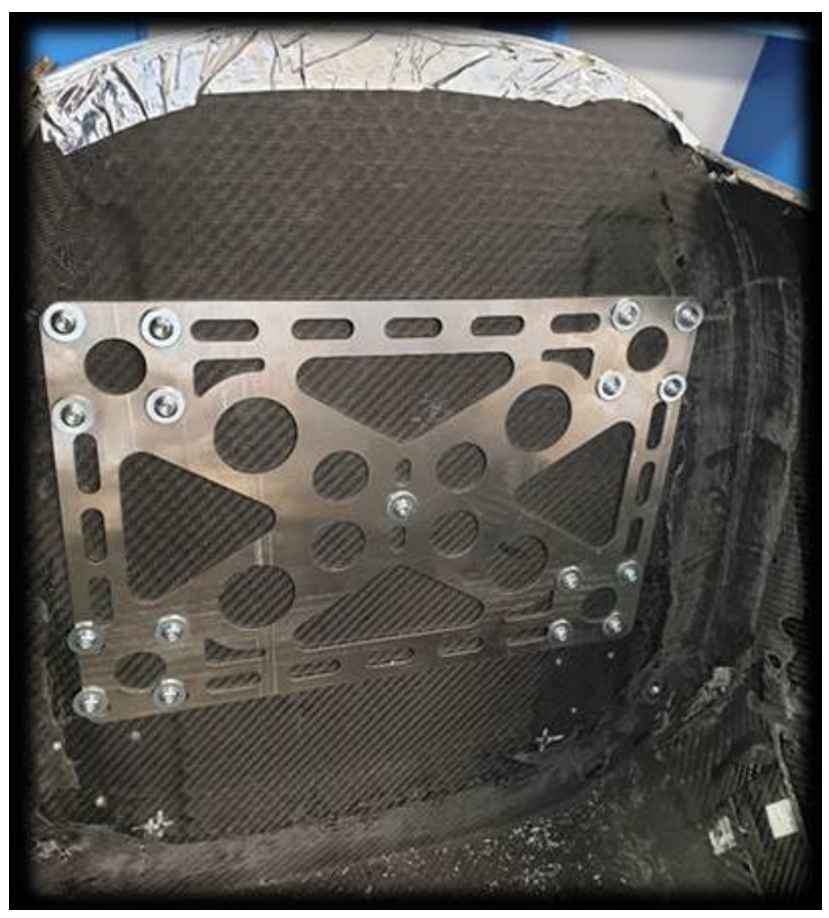

Figure 13: Center plate reinforcement.

\section{Conclusions}

At the Shell eco marathon 2019, we managed to set a new Slovak record when we ran $825 \mathrm{~km}$ for 11 of fuel. So we can say that significant modifications to the engine and both axles have produced results and for us it is additional motivation for the years to continue to develop, to use the knowledge and experience gained from these years and then get closer to European top teams.

The evaluation of the cost of prototype production is specific. It is not possible to rely on standard indicators as in the evaluation of efficiency in serial (mass) production. Such a form of calculation is based on a significantly lower number of pieces produced and to calculate the cost may seem misleading.

Acknowledgement: This work has been supported by grant projects KEGA 045TUKE-4/2019.

\section{References}

[1] C. A. Steeves, "Optimizing sandwich beams for strength and stiffness,”J. Sandw. Struct. Mater., vol. 14, no. 5, pp. 573-595, Sep. 2012.

[2] M. A. A. Alfaiz, M. H. M. Zahir, M. T. Musthafah, R. Herdy, M. S. M. Adrinata, and M. M. Ridzuan, "Design and Development of UTeM 
Perodua Eco-challenge Vehicle," in TRENDS IN AUTOMOTIVE RESEARCH, 2012, vol. 165, pp. 202-208.

[3] G. Kovacs, "Optimization of structural elements of transport vehicles in order to reduce weight and fuel consumption," Struct. Eng. Mech., vol. 71, no. 3, pp. 283-290, 2019.

[4] M. Wang, E. Beeh, P. Zhou, and H. E. Friedrich, “Concept design and dynamics analysis of a novel lightweight vehicle suspension combined with driving units," Proc. Inst. Mech. Eng. Part D J. Automob. Eng., p. 095440701986659, Jul. 2019.

[5] F. Arpino, G. Cortellessa, A. Frattolillo, F. lannetta, and M. Scungio, "Numerical and Experimental Investigation of the Flow over a Car Prototype for the Shell Eco Marathon," J. Appl. FLUID Mech., vol. 12, no. 1, pp. 207-218, Jan. 2019.

[6] E. Abo-Serie, E. Oran, and O. Utcu, "AERODYNAMICS ASSESSMENT USING CFD FOR A LOW DRAG SHELL ECO-MARATHON CAR," J. Therm. Eng., vol. 3, no. 6, 6, pp. 1527-1536, Dec. 2017.

[7] M. Yu, C. Arana, S. A. Evangelou, and D. Dini, "Quarter-Car Experimental Study for Series Active Variable Geometry Suspension," IEEE Trans. Control Syst. Technol., vol. 27, no. 2, pp. 743-759, Mar. 2019.

[8] W. Skarka, T. Pabian, and M. Sosnowski, "Comparison of unibody and frame body versions of ultra efficient electric vehicle," SN Appl. Sci., vol. 1, no. 7, pp. 1-18, 2019.

[9] Y. Putgul and D. Altiparmak, "Vehicle Suspension System Types and Their Effects on Front Axle Geometry," J. Polytech. Derg., vol. 19, no. 2, pp. 195-202, 2016.
[10] B. Nemeth, D. Fenyes, P. Gaspar, and J. Bokor, "Coordination of Independent Steering and Torque Vectoring in a Variable-Geometry Suspension System," IEEE Trans. Control Syst. Technol., vol. 27, no. 5, pp. 2209-2220, 2018.

[11] M. Sumida and K. Hayakawa, "Aerodynamic Forces Acting on Ahmed-Type Vehicles under Fluctuating Headwind Conditions," J. Appl. Fluid Mech., vol. 12, no. 5, pp. 1563-1574, 2019.

[12] P. N. Selvaraju and K. M. Parammasivam, "Empirical and Numerical Analysis of Aerodynamic Drag on a Typical SUV Car Model at Different Locations of Vortex Generator," J. Appl. Fluid Mech., vol. 12, no. 5, pp. 1487-1496, 2019.

[13] D. Wang, S. Zhang, S. Zhang, and Y. Wang, “Analysis and multiobjective optimization design of wheel based on aerodynamic performance," Adv. Mech. Eng., vol. 11, no. 5, pp. 1-19, 2019.

[14] M. Corno, S. Bottelli, G. Panzani, C. Spelta, M. Tanelli, and S. M. Savaresi, "Performance Assessment of Active Aerodynamic Surfaces for Comfort and Handling Optimization in Sport Cars," IEEE Trans. Control Syst. Technol., vol. 24, no. 1, pp. 189-199, 2016.

[15] W. Skarka, T. Pabian, and M. Wasik, "Topology Optimization Approach in a Process of Designing of Composite Shell Structures," in TRANSDISCIPLINARY ENGINEERING METHODS FOR SOCIAL INNOVATION OF INDUSTRY 4.0, 2018, vol. 7, pp. 155-164. control (PPC), Prod. Plan. Control, 2016, 27(5), 360-377 